\title{
Frontal Forebrain Lesions: Effects on the Foraging and Apomorphine Pecking of Pigeons
}

\author{
BRIGITTE WYNNE* AND JUAN D. DELIUS $\dagger^{\prime}$ \\ *Department of Physiology, University of Western Australia, Nedlands WA 6907, Australia and †Allgemeine Psychologie, \\ Universität Konstanz, D 78464 Konstanz, Germany
}

\begin{abstract}
WYNNE, B. AND J. D. DELIUS. Frontal forebrain lesions: Effects of the foraging and apomorphine pecking of pigeons. PHYSIOL BEHAV 59(4/5) 757-762, 1996. - The role of the nucleus basalis prosencephali (Bas), a frontal forebrain structure peculiar to birds, in the control of forage pecking and apomorphine-induced pecking was investigated. In a quasi-natural grit-grain selection task bilateral coagulations of the Bas and the associated neostriatum frontolaterale (Nfl) caused a marked fall in grain per peck uptake and a simultaneous increase in grit per peck uptake. Bas lesions also had a reducing effect on the compulsive pecking elicited by systemic injections of apomorphine. This confirms that the Bas is involved in the control of forage pecking and dopaminergic pecking of birds.
\end{abstract}

$\begin{array}{lcccc}\text { Pigeon } & \text { Pecking } & \text { Feeding } & \text { Apomorphine } & \text { Dopamine } \\ \text { Neostriatum frontolaterale } & \text { Paleostriatum augmentatum } & \text { Lesions } & \text { Nucleus basalis prosencephali }\end{array}$

THE nucleus basalis prosencephali (Bas) is a structure located in the rostral avian telencephalon, and has no known close mammalian counterpart. It receives short latency tactile input from the beak, as well as short latency auditory and vestibular input, relayed by brain stem sensory nuclei through the tractus quintofrontalis $(\mathrm{QF})$ bypassing the thalamus $(1,29,37)$. It may also receive visual inputs from the ectostriatum (E) and olfactory input from the tuberculum olfactorium (TO) $(28,31)$. The Bas itself projects to the overlying neostriatum frontolaterale $(\mathrm{Nfl})$ (36), the source of the tractus fronto-archistriatalis (FA) that reaches the archistriatum anterior $(\mathrm{Aa})(32,38)$. The $\mathrm{Aa}$ in turn contributes to the tractus occipito-mesencephalicus (OM) descending to a variety of brain stem structures (42). At least one of these is involved in pecking: the nucleus reticularis parvocellularis lateralis innervates motor nuclei controlling the jaw musculature $(1,39)$.

The forage peck movements of pigeons can be divided into three phases. During the first phase the location, distance, and size of grains is visually determined and this information controls the initial approach and preparatory gaping motions $(18,33)$. During the second grasping phase motions are principally controlled by tactile, auditory, and taste information $(5,45)$. The third, swallowing phase is presumably influenced by taste and tactile afferences. The anatomy and physiology of the Bas system suggests that it may play a particular role during the second phase. However, experimental evidence confirming such a role is still meagre. Although an early report suggested that Bas lesions themselves led to hypophagia or even aphagia in pigeons (44), later Bas system lesion studies revealed less drastic and sometimes even no effects on feeding activity $(14,19,20,21,24,26,43)$. A more recent study, however, demonstrated that the conditioned control of a pecking/grasping response by auditory and vibratory feedback stimuli was impaired by Bas lesions (30).

The present study accordingly attempted to redefine the degree to which the Bas is implicated in the control of normal forage pecking. Food-deprived pigeons were allowed to feed from a grit-grain mixture. Unlesioned hungry pigeons are known to avidly and selectively pick up and swallow the grains of such mixture $(13,14)$. Occasionally, however, they also pick up grit, which they then mostly drop again and only rarely swallow. But there is also always a proportion of pecks that lead to no particle uptake at all (33). We expected that pigeons with Bas lesions, and possibly also pigeons with Nfl lesions, would be impaired in the effectivity and/or selectivity of grain and grit uptake.

Apomorphine, a potent dopamine agonist, elicits intense pecking behavior in birds $(2,3,40)$. Although the pecks are rarely directed at food and almost never lead to ingestion $(5,20)$, their movement kinetics is quite similar to that of forage pecks (34). A

To whom requests for reprints should be addressed. 
radioactive deoxyglucose labelling study indicated that both apomorphine-induced pecking and food-conditioned pecking activates, among several other brain structures, the Bas/Nfl aggregate (6). Another study reported that apomorphine microinjections into the Bas elicited pecking bouts and that 6-hydroxydopamine-induced lesions of this area decreased the pecking elicited by systemic apomorphine (21).

This stands in contrast with histochemical findings suggesting an absence of dopamine in the Bas and $\mathrm{Nfl}(25,41)$. These studies rather emphasized a high dopamine content of the paleostriatum augmentatum (PA) and of the lobus paraolfactorius (LPO), the presumed avian homologues of the mammalian caudate and putamen. The latter structures have also been shown to be particularly rich in dopamine receptors $(9,21)$. Although there is no evidence that the LPO is involved in the control of pecking, there is some evidence that apomorphine microinjections into the intermediate/caudal PA of pigeons do elicit pecking $(12,20)$. This raises the possibility that the microinjection results mentioned above (21) might have arisen through drug diffusion to the anterior portion of the PA, which borders with the Bas. The present study afforded an opportunity to examine whether nonchemical lesions of the Bas, or indeed, of the frontal PA would affect the compulsive pecking elicited by systemic injections of apomorphine.

\section{METHOD}

Ten pigeons (Columba livia) of local homing stock served as subjects. They were between 6 and 12 months old and weighed between 420 and $467 \mathrm{~g}$. They were kept in individual cages in a well-ventilated and brightly illuminated ( $12 \mathrm{~h}$ on, $12 \mathrm{~h}$ off) animal room. Throughout the experiment they were maintained at $80 \%$ of their normal weight through daily rationed feeding.

Every second day each animal underwent a foraging test $(13,15)$. They were placed in an $45 \times 40 \times 35 \mathrm{~cm}$ observation cage that had three walls lined with red foil. This made it distinct from the experimental cage used in conjunction with apomorphine injections (see below). After the subject had spent $10 \mathrm{~min}$ in this cage, a transparent feeding trough $(9 \times 5 \times 6 \mathrm{~cm})$ was attached below and outside a $10 \times 8 \mathrm{~cm}$ opening in the wire mesh front wall. The trough contained 30 safflower grains mixed with $30 \mathrm{~g}$ (about a 1000) grit particles similar in size, shape, and color to the grains. The feeding behavior of the bird was videographed. Thirty seconds after the pigeon had first pecked at the mixture the trough was removed. The grains left in the mixture were counted and the remaining grit was weighed. The pecks directed at the mixture were counted using the slow motion video replay mode. These counts served as indices of the pigeon's pecking activity. The number of grains consumed and the number of 10 $\mathrm{mg}$ units of grit removed were separately expressed as percentages of the number of pecks counted. Of course, additional grit may have been picked up but immediately been dropped again into the trough, thus escaping notice. The resulting indices were therefore respectively a precise indicator of the peck's effectivity in yielding grain uptake and an analogous but relative indicator of the peck's effectivity in yielding grit uptake. Combined the indices can be viewed as reflecting the grain vs. grit uptake selectivity. Each bird was subjected to 10 preoperative (preop.) foraging tests.

On the alternate days the pigeons were injected with apomorphine into the pectoral muscle. Half of the subjects began with a series of 12 injections of $0.2 \mathrm{mg} / \mathrm{kg}$, the other half with a series of 12 injections of $0.5 \mathrm{mg} / \mathrm{kg}$. Then each group received a further 12 injections with the converse dosage. The first six injections of each dosage series served to bring about the sensitization to the drug known to accompany initial injections $(2,3)$ and the following six sessions to provide preop. peck activity baselines. Immediately after each injection the animal was placed in an experimental cage. To promote pecking, three of its walls were lined with black foil peppered with yellow dots $(8 \mathrm{~mm}$ diameter, 10 per $\left.\mathrm{dm}^{2}\right)(2,3)$. The unobstructed front faced a observation cubicle with a one-way screen. Beginning $5 \mathrm{~min}$ after the injection all pecks issued during the following $20 \mathrm{~min}$ were counted.

When the preop. treatments were completed the subjects were divided into a group of six birds targeted for Bas lesions and another group of four birds targeted for control lesions. Both groups were approximately matched for preop. foraging performance and apomorphine pecking. The surgery was performed under general pentobarbital/chloral hydrate anaesthesia (22). A metal olive that served as reference electrode was slipped into the rectum. While the head was held in a stereotaxic instrument, the scalp was incised and trephines were bilaterally drilled through the bone above the target structures. An insulated stainless steel electrode $(0.3 \mathrm{~mm}$ diameter, with an exposed parabolic $0.5 \mathrm{~mm}$ tip) was lowered into the brain tissue to coordinates taken from the pigeon brain atlas (17) and selected as to destroy as much of the Bas as possible. In each telencephalic hemisphere a lesion was thus created by passing high frequency current $(25 \mathrm{~mA}, 10 \mathrm{~s})$ at four separate but clustered sites (approximately $1.5 \mathrm{~mm}$ apart). The control coagulations were analogously placed but $4 \mathrm{~mm}$ more posteriorly and dorsally. After skin-suturing each animal was allowed 7 days of recovery.

The pigeons were then given 10 postoperative (postop.) foraging tests following the same routine described earlier, one every second day. They were tested for apomorphine-induced pecking on the alternate days. Half of the subjects were first administered a series of six $0.2 \mathrm{mg} / \mathrm{kg}$ and then a series of six $0.5 \mathrm{mg} / \mathrm{kg}$ doses, the other half receiving the same dosages in the converse order.

Upon completion of the behavioral tests, the pigeons were injected with an overdose of anaesthetic and perfused transcardially with saline and formaline. After postfixation the brains were removed from the skull. The brain of one control lesioned bird was accidentally destroyed at this stage. Its data was discarded. The remaining brains were cut into $40-\mu \mathrm{m}$ sections with a cryotome. The sections were mounted on slides, stained with cresyl violet, and coverslipped. Microscopic inspection revealed grossly misplaced and oversized lesions in a further control subject. Its sections and data were also discarded. A microscope equipped with a computerized image analyzer was used to determine the total lesion volumes and the partial lesion volumes affecting the various structures. Sections corresponding to the $0.25-\mathrm{mm}$ spaced frontal planes of the brain atlas (17) of each brain were displayed on the system's monitor. The outlines of the lesioned tissue and the various structures were traced with a

TABLE

LESION VOLUMES OF Bas, Nfl, PA., AND OTHER STRUCTURES AS WELL AS TOTAL VOLUMES IN $\mathrm{mm}^{3}$

\begin{tabular}{llllll}
\hline Bird & Bas & Nfl & PAf & Other & Total \\
\hline$\# 2$ & 2.89 & 7.22 & 0.55 & 0.00 & 10.66 \\
$\# 4$ & 2.66 & 1.08 & 0.10 & 0.00 & 3.84 \\
$\# 5$ & 2.09 & 3.11 & 0.60 & 0.23 & 6.03 \\
$\# 1$ & 1.74 & 0.53 & 0.84 & 0.00 & 3.11 \\
$\# 8$ & 1.41 & 1.13 & 1.20 & 0.20 & 3.94 \\
$\# 9$ & 0.44 & 0.88 & 0.51 & 0.37 & 2.25 \\
$\# 7$ & 0 & 0 & 0 & 9.93 & 9.93 \\
$\# 6$ & 0 & 0 & 0 & 9.12 & 9.12 \\
\hline
\end{tabular}

The experimental pigeons are ordered according to decreasing Bas lesion volumes; pigeons \#7 and \#6 were controls. 


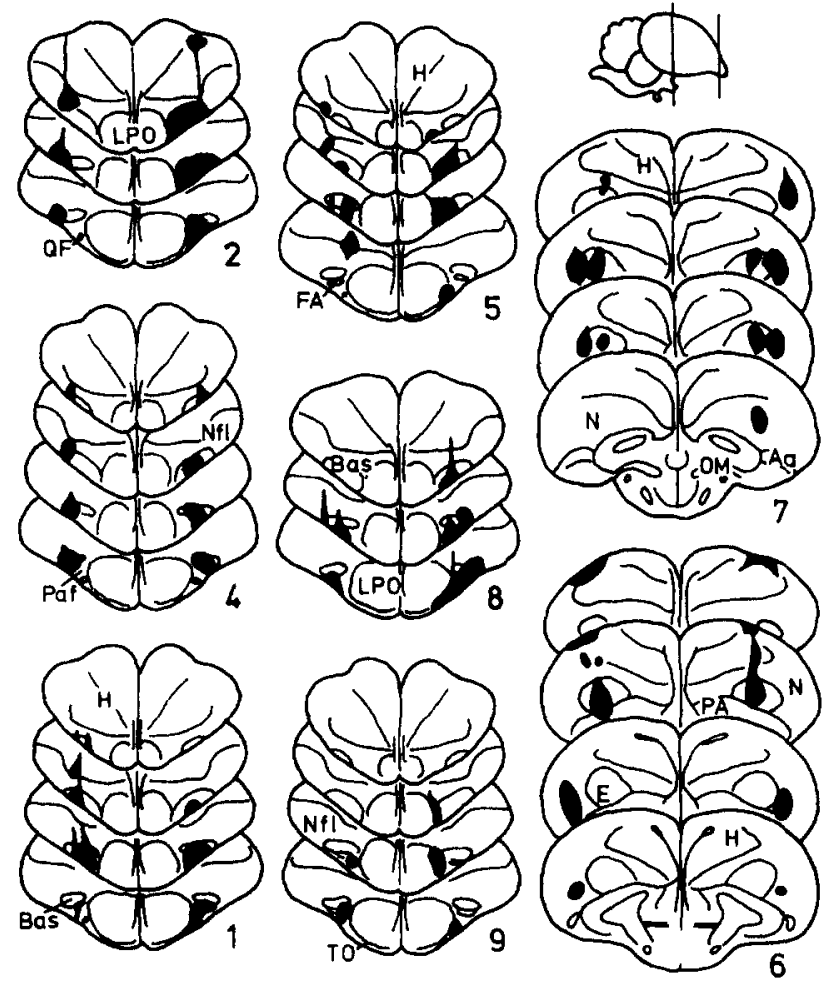

FIG. 1. Lesions sustained by experimental (left columns) and control pigeons (right column). For abbreviations see text, except $\mathrm{H}$ : hyperstriatum.

mouse driven cursor. A planimetric option computed the various areas and after entering the above spacing, it yielded the corresponding volumes. For illustration purposes the lesions were also transferred to diagrams taken from the same atlas.

\section{RESULTS}

The lesions sustained by the eight remaining birds are shown in Fig. 1. All the experimental lesions affected the Bas, although to varying degrees. They also impinged to various extents on some of the neighboring structures, the QF, the Nfl, the FA, and the PAf, as the most anterior tongue-like extension of the PA will be called here. The LPO was only very slightly touched in three birds. The control lesions affected the intermediate-lateral neostriatum $(N)$, the ectostriatum $(E)$, and in one instance, slightly, the intermediate PA. Table 1 lists the total lesion volumes and details those pertaining to the Bas, the Nfl, and the PAf and other structures for each of the birds. The QF tract damages were nearly coextensive with the Bas lesions. However, both FA tracts were completely transected at a level posterior to the Bas in subjects \#1 and \#8, which had otherwise sustained only lesser Bas and Nfl lesions. The largest lesions of the Bas in pigeon \#2 incidentally encompassed just $50 \%$ of its volume. The $\mathrm{Nfl}$ has not yet been appropriately delimited against the surrounding frontal $\mathrm{N}$ but an approximate estimate is that the largest lesion in pigeon \#2 encompassed about $40 \%$ of the Nfl volume. The PAf has been even less well separated from the main body of the PA but a rough estimate is that the largest lesion of the PAf in pigeon \#8 affected about $50 \%$ of it. None of the lesions were of course fully symmetric (Fig. 1) but because in the event this fact was found not to have significantly influenced any of the results mentioned later, the asymmetries are not detailed in Table 1.
TABLE 2

AVERAGE PREOP. AND PREOP. GRAIN AND GRIT UPTAKE INDICES

\begin{tabular}{cccccc}
\hline & \multicolumn{2}{c}{ Grain } & \multicolumn{2}{c}{ Grit } \\
\cline { 2 - 3 } \cline { 5 - 6 } Bird & Preop. Index & $\begin{array}{c}\text { Postop. Index } \\
\text { (\% Change) }\end{array}$ & Preop. Index & $\begin{array}{c}\text { Postop. Index } \\
\text { (\% Change) }\end{array}$ \\
\hline$\# 2$ & 37 & $1(2)$ & 10 & $21(204)$ \\
$\# 4$ & 48 & $8(16)$ & 8 & $33(414)$ \\
$\# 5$ & 21 & $0(0)$ & 40 & $41(103)$ \\
$\# 1$ & 44 & $42(93)$ & 12 & $14(120)$ \\
$\# 8$ & 52 & $20(40)$ & 5 & $19(382)$ \\
$\# 9$ & 40 & $34(85)$ & 14 & $10(71)$ \\
$\# 7$ & 20 & $21(105)$ & 23 & $15(67)$ \\
$\# 6$ & 54 & $57(106)$ & 4 & $2(53)$ \\
\hline
\end{tabular}

The postop. indices are expressed as percents of the preop. indices in parentheses. As in Table 1, the pigeons are ordered according to decreasing Bas damage.

The individual mean postop. pecking rates were expressed as percents of the mean preop. rates. These percentages did not correlate significantly with either the Bas, the Nfl, the PAf, or the total volumes lesioned. But it is pertinent to point out that the average per session rate rose from preop. 22 pecks to postop. 68 pecks, an increment of $209 \%$. This no doubt reflected the fact that the pigeons became increasingly confident with the foraging test situation. Any effects of the lesions on the general pecking activity may have been obscured by the substantial increment in pecking activity. The mean grain and grit uptake indices for the both the preop. and postop. phases of each pigeon are listed in Table 2. The postop. scores are also expressed as percents of the preop. scores.

The magnitudes of the postop. percent grain uptake changes were negatively and significantly correlated with the size of the individual Bas lesions (Spearman's $r_{\mathrm{s}}=-0.86, n=8, p<0.01$ ) and Nfl lesions $\left(r_{\mathrm{s}}=-0.95, p<0.001\right)$. This effect is also documented in Fig. 2 showing the preop. and postop. mean course of the grain uptake effectiveness index separately for the four least (L) and the four most (M) Bas and Nfl lesioned pigeons. It is patent that from a similar preop. baseline these two groups of subjects show a diverging postop. course that accords with the above correlations. In an approximately converse manner the magnitude of the grit postop. percent uptake changes

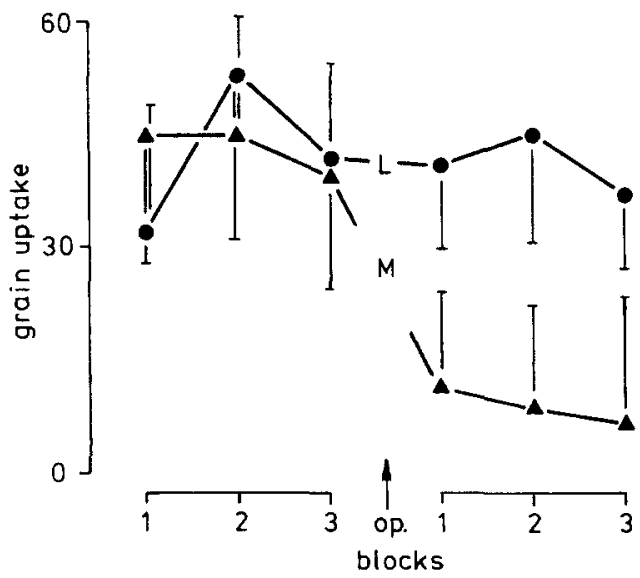

FIG. 2. Mean grain uptake indices with standard deviations during the nine last preop. and the nine first postop. foraging tests, plotted in blocks of threee, for the four least (L) and the four most (M) Bas plus Nfl-lesioned pigeons. 
increased significantly with Bas lesion sizes $\left(r_{\mathrm{s}}=+0.77, p<\right.$ $0.05)$ and with NFL lesion sizes $\left(r_{\mathrm{s}}=+0.67, p \approx 0.05\right)$. Because the extents of Bas and Nfl lesions correlated across subjects $\left(r_{\mathrm{s}}=+0.83, p<0.01\right.$; compare Table 1) partial correlations were also computed. As these revealed no significant changes in coefficient magnitudes it must be concluded that both Bas and Nfl lesions contributed about equally to the postop. effects upon both grain and grit uptake effectivity. Contrasting with this, neither PAf lesion extents nor total lesion volumes correlated significantly with the postop. uptake changes. The results thus establish that in a quasinatural foraging situation, damages to the Bas/Nfl complex impair the pigeons' grain vs. grit uptake selectivity.

Regarding the pecking induced by the apomorphine injections, Table 3 presents the subject's mean pecking rates for the last six preop. sessions and for the six postop. sessions. The latter are also listed as percents of the former. As already indicated, only the six last preop. sessions with each dose were used as baselines because many of the early preop. session scores were, as was expected, affected by steep increases in responding. These increases undoubtedly reflected the well-known sensitization process obtaining with first apomorphine injections whenever these exceed a minimum dose $(2,3,40)$.

The postop. changes in pecking frequency corresponding to the $0.2 \mathrm{mg} / \mathrm{kg}$ dose did not correlate significantly with either the Bas, Nfl, PAf, or the total lesion volumes. However, because of the accidental drop-out of two subjects and some uncontrollable lesion size variations in the remaining pigeons there was, despite the initially balanced experimental design, an unfortunate correlation between the low-high and high-low dose preop. treatment sequences (see the Method section) and the sizes of the Bas lesions. In conjunction with a quantitatively somewhat asymmetric transfer of drug sensitization from one dose to the other dose, this imbalance resulted in skewed preop. baselines for the 0.02 $\mathrm{mg} / \mathrm{kg}$ apomorphine condition (Table 3 ). The mean preop. pecking rate for the four most Bas lesioned birds is significantly lower than that for the four least or not Bas-lesioned birds [WilcoxonMann-Whitney, $W(4,4)=11, p<0.05$ ]. A potential Bas lesion effect may have been masked by this unfortunate baseline bias.

The baselines corresponding to the $0.5 \mathrm{mg} / \mathrm{kg}$ dose data were not affected by any such problem. The negative correlation between the extent of Bas lesions and the postop. percent response changes $\left(r_{\mathrm{s}}=-0.67, p \approx 0.05\right)$ obtained with this dose was therefore unconstrained. The correlations with Nfl, PAf, and total lesion volumes were all not significant. Interestingly, a

TABLE 3

MEAN PREOP. AND POSTOP. NUMBER OF PECKS PER SESSION WITH POSTOP. PERCENT CHANGES IN PARENTHESES, FOR 0.2 AND $0.5 \mathrm{mg} / \mathrm{kg}$ APOMORPHINE DOSES

\begin{tabular}{cccccc}
\hline & \multicolumn{2}{c}{$0.2 \mathrm{mg} / \mathrm{kg}$} & & \multicolumn{2}{c}{$0.5 \mathrm{mg} / \mathrm{kg}$} \\
\cline { 2 - 3 } \cline { 5 - 6 } Bird & Preop. Rate & $\begin{array}{c}\text { Postop. Rate } \\
\text { (\% Change) }\end{array}$ & Preop. Rate & $\begin{array}{c}\text { Postop. Rate } \\
\text { (\% Change) }\end{array}$ \\
\hline \#2 & 34 & $159(467)$ & 918 & $909(99)$ \\
$\# 4$ & 59 & $859(1456)$ & 1445 & $1006(70)$ \\
$\# 5$ & 46 & $1046(2273)$ & 2312 & $2637(114)$ \\
$\# 1$ & 184 & $1204(654)$ & 2556 & $2291(90)$ \\
$\# 8$ & 655 & $1112(169)$ & 1075 & $1269(118)$ \\
$\# 9$ & 233 & $910(390)$ & 1309 & $1918(146)$ \\
$\# 7$ & 1871 & $989(53)$ & 1927 & $1983(103)$ \\
$\# 6$ & 80 & $1379(1723)$ & 1195 & $1846(154)$ \\
\hline
\end{tabular}

The pigeons are ordered according to decreasing Bas lesion sizes. partialling-out of the insignificant Nfl lesion effects nevertheless augmented markedly the correlation between the Bas lesion sizes and the percent changes in drug effectiveness $\left(r_{\mathrm{s}}=-0.87, p<\right.$ $0.01)$. We thus must assume that the postop. decrements due to Bas lesions were genuine, even though the overall effect magnitude was relatively small. The four most Bas-lesioned pigeons yielded a mean postop. pecking rate fall to $93 \%$ whereas the four least or not Bas-lesioned pigeons produced a mean postop. rise in apomorphine-induced pecking to $130 \%$.

\section{DISCUSSION}

The results show that lesions of both the Bas and the Nfl decrease the efficiency of forage pecking, more affected pigeons becoming less selective in grasping grain instead of grit. We have also found that Bas lesions diminishes the compulsive pecking induced by peripheral injections of a medium effect dose of apomorphine, a dopamine agonist.

This latter conclusion admittedly focuses on the results obtained with the $0.5 \mathrm{mg} / \mathrm{kg}$ dose, because, as explained, the absence of an effect with the lower $0.2 \mathrm{mg} / \mathrm{kg}$ dose could easily be due to the preop. baseline problems reported. The significant inverse relationship between postop. drug response changes and Bas lesion extents obtained with the higher dose agrees with the notion that the Bas is partly involved in the control of pecking induced by systemically administered apomorphine, as already suggested by an intracerebral microinjection study (21). The alternative that the results of this latter study were due to drug diffusion to the neighboring PA is unlikely insofar as in the present study lesions of the PAf were not found to have a depressing effect on apomorphine pecking. Incidentally, the lesion effects reported preliminary in ref, 41 are based on erroneous computations and should be disregarded.

This finding apparently conflicts with imunohistological data showing that although the LPO, the PA, and specifically the PAf of pigeons contains high levels of dopamine and tyrosine-hydroxylase, the Bas is virtually free of these substances $(25,41)$. This is in some concordance with the results of studies reporting high densities of dopamine receptors in the pigeon's PA and LPO but not specifically excluding the presence of lesser receptor densities in the Bas $(9,27)$. Additional research, taking into account the increased variety of dopamine receptors (4), is needed before it can be definitively decided whether the Bas is furnished with some dopaminoceptivity or not. It is symptomatic that recent evidence indicates that low densities of dopamine receptors are quite widespread in at least the mammalian forebrain, occurring even in several structures that previously had been thought to be free of dopamine (23).

In that context it is worth repeating that apomorphine microinjection into the PA (but not into the LPO) undoubtedly can also trigger pecking bouts $(12,20,21)$ and that lesions of this structure also depress the pecking induced by systemic apomorphine administration (11). However, these effects appear to be connected with the caudal PA and not to appertain to the frontal PA that concerns us here. Indeed, the already mentioned metabolic labelling study (7) revealed that besides the BAS/Nfl complex, and among several further brain structures, the caudal PA, but not the PAf, was metabolically activated by systemic apomorphine injections eliciting pecking.

The results of the grit-grain discrimination tests show that lesions of the Bas and Nfl complex lower the pigeon's effectiveness of grasping grains instead of grit in a manner proportional to the extent of the damage to these structures, without significantly affecting the basic pecking rate. This is in agreement with the connectivity of the Bas and $\mathrm{Nfl}$ and with the results of the more recent Bas system deafferentation studies showing specialized 
food uptake impairments (24). In particular, they accord well with the demonstration that an operantly discriminative pecking/grasping response controlled by auditory and vibratory feedback stimuli was impaired after Bas lesions in pigeons (30).

FA lesions could be expected to de-efferent the Bas/Nfl complex and thus have more drastic effects than any partial lesions of these latter structures. We observed nothing of the kind in the two relevant birds (\#1 and \#8) of this study. This replicates results obtained employing the same grit-grain task and circumscribed FA transections (14). The same study found, however, that lateral $\mathrm{N}$ lesions at more caudal levels produced grit-grain discrimination deficits of a similar nature as those described here after more frontal Bas/Nfl lesions. This agrees with the fact that, in addition to the FA, the Nfl may have efferents projecting to, or coursing through, the lateral telencephalon $(10,32)$.

The foraging test employed is naturally too coarse to permit by itself a definite ascription of the deficits observed. The most likely account is that the pigeons with Bas/Nfl lesions had difficulties with the selective grasping of grains instead of grit because of the tactile-auditory feedback impairments mentioned above. A less likely account is that the pigeons had trouble with visually and selectively aiming their pecks at grains instead of grit. This latter explanation might apply more to the aforementioned foraging performance deficits after lateral intermediate $\mathrm{N}$ lesions, as this area is definitely known to have visual functions (6).

At this point, however, it is worth noting that even forebrainless pigeons are able to peck and feed on grains, although with greater difficulty than normal ones $[(8,35)$; see $(16)]$. Foraging is such a primary behavior that the essential mechanisms coordinating it must be suspected to be located in the most basal parts of the vertebrate brain. Indeed, the arguably most striking pattern of peck-induced metabolic activation identified through deoxyglucose labelling concerns the cerebellum (7). In this light it may be wise to consider the nucleus basalis prosencephali (Bas) and other relevant telencephalic areas only as high level components of a pecking control system whose more essential elements are located at lower levels of the avian neuraxis.

\section{ACKNOWLEDGEMENTS}

While carrying out the research at the Allgemeine Psychologie, Universität Konstanz, Germany, B.W. was a recipient of a grant by the Graduiertenförderung Baden-Württemberg. The work was supported by grants of the Deutsche Forschungsgemeinschaft to J.D.D. We are grateful to Prof. O. Güntürkün (Bochum) for much advice, Dr. R. Jäger for criticizing a draft, K. Lindlar for assistance with statistics, G. Latini for improving the English, and A. McLintock for help with manuscript preparation.

\section{REFERENCES}

1. Berkhoudt, H.; Dubbeldam, J. L.; Zeilstra, S. Studies on the somatotopy of the trigeminal system in the mallard Anas platyrhynchos L. IV. Tactile representation in the nucleus basalis. J. Comp. Neurol. 196:407-420; 1981 .

2. Brunelli, M.; Magni, F.; Moruzzi, G.; Musumeci, D. Apomorphine pecking in the pigeon. Arch. Ital. Biol. 113:303-325; 1975.

3. Burg, B.; Haase, C.; Lindenblatt, U.; Delius, J. D. Sensitization to and conditioning with apomorphine in pigeons. Pharmacol. Biochem. Behav. 34:59-64; 1989.

4. Civelli, O. Molecular biology of the dopamine receptor subtypes. In: Bloom, F. E.; Kupfer, D. J., eds. Psychopharmacology, the fourth generation of progress. New York: Raven; 1995:155-161.

5. Delius, J. D. The pecking of the pigeon: Free for all. In: Lowe, C. F.; Richelle, M.; Blackman, D. E.; Bradshaw, C. M., eds. Behavior analysis and contemporary psychology. New York: Erlbaum; 1985:53-81.

6. Delius, J. D.; Jäger, R.; Friesel, M. Lateral telencephalic lesions affect visual discrimination in pigeons. Behav. Brain. Res. 11:249 $258 ; 1984$.

7. Delius, J. D.; Scheich, H. Deoxyglucose incorporation by the pigeon brain during apomorphine and instrumental pecking (submitted).

8. De Souza, C. M. Z.; Britto, L. R. G.; Ferrari, E. A. Keypecking operant conditioning in detelencephalated pigeons (Columba livia). Behav. Brain Res. 28:223-232; 1990.

9. Dietl, M. M.; Palacios, J. M. Neurotransmitter receptors in the avian brain. I. Dopamine receptors. Brain Res. 439:354-359; 1988.

10. Dubbeldam, J. L. Neuronal circuits of the feeding system in birds. Fortschr. Zool. 30:273-275; 1985

11. Goodman, I.; Azzaro, A. J. Pecking and circling in pigeons following destruction of a tegmentopaleostriatal pathway, a possible nigrostriatal homologue. Soc. Neurosci. Abstr. 4:301; 1978.

12. Goodman, I.; Stitzel, R. E. Corpus striatum (paleostriatal complex) interactions and stereotyped behavior in pigeons. Soc. Neurosci. Abstr. 3:37; 1977.

13. Güntürkün, O.; Kesch, S. Visual lateralization during feeding in pigeons. Behav. Neurosci. 101:433-435; 1987.

14. Jäger, R. Visuomotor feeding perturbations after lateral telencephalic lesions in pigeons. Behav. Brain Res. 40:73-80; 1990.

15. Jäger, R. Lateral forebrain lesions affect pecking accuracy in the pigeon. Behav. Proc. 28:181-188; 1993.

16. Jäger, R.; Arends, J. J. A.; Schall, U.; Zeigler, H. P. The visual forebrain and eating in pigeons (Columba livia). Brain Behav. Evol. 39: 153-168; 1992.

17. Karten, H. J.; Hodos, W. A stereotaxic atlas of the brain of the pigeon (Columba livia). Baltimore: Johns Hopkins; 1967.

18. Klein, B. G.; Deich, J. D.; Zeigler, H. P. Grasping in the pigeon (Columba livia): Final common path mechanisms. Behav. Brain Res. $18: 201-213 ; 1985$.

19. Kuenzel, W. J. Transient aphagia produced following bilateral destruction of the lateral hypothalamic area and quinto frontal tract of chicks. Physiol. Behav. 28:237-244; 1982.

20. Lindenblatt, U. Die dopaminerge Auslösung des Pickverhaltens bei Tauben. Ph.D. thesis, Ruhr Universität Bochum; 1986.

21. Lindenblatt, U.; Delius, J. D. Nucleus basalis prosencephali, a substrate of apomorphine induced pecking in pigeons. Brain Res. 453:1 $8 ; 1988$.

22. Mallin, H. D.; Delius, J. D.; Inter- and intraocular transfer of color discriminations with mandibulation as an operant in the head fixed pigeon. Behav. Anal. Lett. 3:297-309; 1983.

23. Mansour, A.; Watson, S. J. Dopamine receptor expression in the central nervous system. In: Bloom, F. E.; Kupfer, D. J., eds. Psychopharmacology, the fourth generation of progress. New York: Raven; 1995:207-219.

24. Miller, M. G.; Zeigler, H. P.; Miller, A. E. Trigeminal deafferentation and feeding behavior in the pigeon (Columba livia). J. Comp. Physiol. Psychol. 92:1025-1040; 1978.

25. Parent, A.; Poitras, D.; Dubé, L. Comparative anatomy of the central monoaminergic systems. In: Björklund, A.; Hökfelt, T., eds. Handbook of chemical neuroanatomy, vol. 2. Classical transmitters in the CNS, part 1. Amsterdam: Elsevier; 1984:409-439.

26. Ramirez, J. M. Forebrain lesions and food intake in pigeons. Physiol. Behav. 23:981-984; 1979.

27. Richfield, E. K.; Young, A.; Penney, J. B. Comparative distribution of the dopamine $D_{1}$ and $D_{2}$ receptors in the basal ganglia of turtles, pigeons, rats, cats and monkeys. J. Comp. Neurol. 262:446-463; 1987.

28. Schall, U. Vestibular, olfactory, and vibratory of nucleus basalis prosencephali, a feeding pecking center in the pigeon. Neurosci. Res. 4:376-384; 1987.

29. Schall, U.; Delius, J. D. Sensory input to the nucleus basalis prosencephali, a feeding pecking centre in the pigeon. J. Comp. Physiol. [A] $159: 33-41 ; 1986$ 
30. Schall, U.; Delius, J. D. Grasping in the pigeon: Control through sound and vibration feedback mediated by the nucleus basalis. Physjol. Behav. 50:983-988; 1991.

31. Schall, U.; Güntürkün, O.; Delius, J. D. Sensory projections to the nucleus basalis prosencephali of the pigeon. Cell Tissue Res. 245:539-546; 1986.

32. Showers, M. J. C. Telencephalon of birds. In: Crosby, E. C.; Schnitzlein, H. N., eds. Comparative correlative neuroanatomy of the vertebrate telencephalon. New York: Macmillan; 1982:219-246.

33. Siemann, M.; Delius, J. D. Variability of forage pecking in pigeons. Ethology 92:29-50; 1992.

34. Siemann, M.; Delius, J. D. Apomorphine induced behavior in pigeons (Columba livia). In: Elsner, N.; Richter, N. R., eds. Rhythmogenesis in neurons and networks. Stuttgart: Thieme; 1992:600.

35. Thauer, R.; Peters, G. Sensibilität und Motorik bei lang überlebenden Zwischen-Mittelhirntauben. Pflügers Arch. Ges. Physiol. 240:503$526 ; 1938$.

36. Veeneman, C. L.; Gotschaldt, U. M. The nucleus basalis neostriatum complex in the goose (Anser anser L.). Adv. Anat. Embryol. Cell. Biol. 96:71-74; 1986.

37. Wild, J. M.; Arends, J. J. A.; Zeigler, H. P. A trigeminal sensorimotor circuit for pecking, grasping and feeding in the pigeon (Columba livia). Brain Res. 300:146-151; 1984.
38. Wild, J. M.; Arends, J. J. A.; Zeigler, H. P. Telencephalic connections of the trigeminal system in the pigeon (Columba livia): A trigeminal circuit. J. Comp. Neurol. 234:441-464; 1985.

39. Wild, J. M.; Zeigler, H. P. Central representations of jaw muscles within the facial and trigeminal nuclei of the pigeon (Columba livia) J. Comp. Neurol. 192:175-201; 1980.

40. Wynne, B.; Delius, J. D. Sensitization to apomorphine in pigeons due to classical conditioning but still unaffected by latent inhibition. Psychopharmacology (Berlin) 119:414-420; 1995.

41. Wynne, B.; Güntürkün, $O$. The dopaminergic innervation of the telencephalon in the pigeon (Columba livia): A study with antibodies against tyrosine hydroxylase and dopamine. J. Comp. Neurol. $357: 446-464 ; 1995$.

42. Zeier, H.; Karten, H. J. The archistriatum of the pigeon: Organization of afferent and efferent connections. Brain Res. 31:313-326; 1981.

43. Zeigler, H. P. Feeding behavior of the pigeon. Adv. Study Behav. 7:285-389; 1976.

44. Zeigler, H. P.; Karten, H. J.; Green, H. L. Neural control of feeding in the pigeon. Psychon. Sci. 15:156-157; 1969.

45. Zweers, G. A. Pecking of the pigeon (Columba livia L.). Behaviour 81:175-230; 1982. 